\title{
Morphological and functional heterogeneity of the mouse intrahepatic biliary epithelium
}

\author{
Shannon S Glaser ${ }^{1,2,15, *}$, Eugenio Gaudio ${ }^{3,15}$, Arundhati Rao ${ }^{4,5,6}$, Lisa M Pierce ${ }^{7}$, Paolo Onori ${ }^{8}$, Antonio Franchitto ${ }^{3}$, \\ Heather L Francis ${ }^{2,9}$, David E Dostal ${ }^{10,11}$, Julie K Venter ${ }^{2}$, Sharon DeMorrow ${ }^{1,2}$, Romina Mancinelli ${ }^{1,3}$, \\ Guido Carpino $^{12}$, Domenico Alvaro ${ }^{13}$, Shelley E Kopriva ${ }^{10}$, Jennifer M Savage ${ }^{2}$ and Gianfranco D Alpini ${ }^{1,2,10,14}$
}

Rat and human biliary epithelium is morphologically and functionally heterogeneous. As no information exists on the heterogeneity of the murine intrahepatic biliary epithelium, and with increased usage of transgenic mouse models to study liver disease pathogenesis, we sought to evaluate the morphological, secretory, and proliferative phenotypes of small and large bile ducts and purified cholangiocytes in normal and cholestatic mouse models. For morphometry, normal and bile duct ligation (BDL) mouse livers (C57/BL6) were dissected into blocks of 2-4 $\mu \mathrm{m}^{2}$, embedded in paraffin, sectioned, and stained with hematoxylin and eosin. Sizes of bile ducts and cholangiocytes were evaluated by using SigmaScan to measure the diameters of bile ducts and cholangiocytes. In small and large normal and BDL cholangiocytes, we evaluated the expression of cholangiocyte-specific markers, keratin-19 (KRT19), secretin receptor (SR), cystic fibrosis transmembrane conductance regulator (CFTR), and chloride bicarbonate anion exchanger $2\left(\mathrm{Cl}^{-} / \mathrm{HCO}_{3}^{-} \mathrm{AE} 2\right)$ by immunofluorescence and western blot; and intracellular cyclic adenosine $3^{\prime}, 5^{\prime}$-monophosphate (cAMP) levels and chloride efflux in response to secretin $(100 \mathrm{nM})$. To evaluate cholangiocyte proliferative responses after BDL, small and large cholangiocytes were isolated from BDL mice. The proliferation status was determined by analysis of the cell cycle by fluorescence-activated cell sorting, and bile duct mass was determined by the number of KRT19-positive bile ducts in liver sections. In situ morphometry established that the biliary epithelium of mice is morphologically heterogeneous, with smaller cholangiocytes lining smaller bile ducts and larger cholangiocytes lining larger ducts. Both small and large cholangiocytes express KRT19 and only large cholangiocytes from normal and BDL mice express SR, $\mathrm{CFTR}$, and $\mathrm{Cl}^{-} / \mathrm{HCO}_{3}^{-}$ exchanger and respond to secretin with increased cAMP levels and chloride efflux. Following BDL, only large mouse cholangiocytes proliferate. We conclude that similar to rats, mouse intrahepatic biliary epithelium is morphologically and functionally heterogeneous. The mouse is therefore a suitable model for defining the heterogeneity of the biliary tree. Laboratory Investigation (2009) 89, 456-469; doi:10.1038/labinvest.2009.6; published online 9 February 2009

KEYWORDS: bicarbonate secretion; cAMP; cholangiocytes; secretin; secretin receptor

In recent years, knowledge associated with biliary epithelial cell (ie, cholangiocytes) function has been significantly enhanced due to increased interest in cholestatic liver diseases, biliary fibrosis, and biliary cancer. ${ }^{1-6}$ Cholangiocytes were originally termed as 'simple' epithelia, which line the intrahepatic and extrahepatic bile ducts. ${ }^{7-9}$ Despite the original terminology of 'simple epithelia', cholangiocytes play an important role in the modification of ductal bile, as well as in

\footnotetext{
${ }^{1}$ Scott and White Digestive Diseases Research Center, Temple, TX, USA; ${ }^{2}$ Department of Medicine, Scott and White Hospital and Texas A\&M Health Science Center, College of Medicine, Temple, TX, USA; ${ }^{3}$ Department of Anatomy, University of Rome, Rome, Italy; ${ }^{4}$ Section of Technical Pathology, Scott and White Hospital and Texas A\&M Health Science Center, College of Medicine, Temple, TX, USA; ${ }^{5}$ Section of Molecular Genetics, Scott and White Hospital and Texas A\&M Health Science Center, College of Medicine, Temple, TX, USA; ${ }^{6}$ Department of Pathology, Scott and White Hospital and Texas A\&M Health Science Center, College of Medicine, Temple, TX, USA; ${ }^{7}$ Department of Obstetrics and Gynecology, Scott and White Hospital and Texas A\&M Health Science Center, College of Medicine, Temple, TX, USA; ${ }^{8}$ Department of Experimental Medicine, University of L'Aquila, L'Aquila, Italy; ${ }^{9}$ Division of Research and Education, Scott and White Hospital, Temple, TX, USA; ${ }^{10}$ Division of Research, Central Texas Veterans Health Care System, Temple, TX, USA; ${ }^{11}$ Department of Molecular Cardiology, Scott and White Hospital, Temple, TX, USA; ${ }^{12}$ Department of Health Science, IUSM, University of Motor Sciences, Rome, Italy; ${ }^{13}$ Department of Gastroenterology, University of Rome, Rome, Italy and ${ }^{14}$ Department of Systems Biology and Translational Medicine, Scott and White Hospital and Texas A\&M Health Science Center, College of Medicine, Temple, TX, USA

*Correspondence: Dr S Glaser, PhD, Department of Medicine, Scott and White Hospital and Texas A\&M Health Science Center College of Medicine, 702 SW HK Dodgen Loop, Temple, TX, 76504, USA. E-mail: sglaser@tamu.edu or Dr G Alpini, PhD, Division of Research, Central Texas Veterans Health Care System, Scott and White Hospital and Texas A\&M Health Science Center College of Medicine, Medical Research Building, 702 SW HK Dodgen Loop, Temple, TX, 76504, USA. E-mail: galpini@tamu.edu or galpini@medicine.tamhsc.edu

${ }^{15}$ These authors contributed equally to this work.
}

Received 10 October 2008; revised 4 December 2008; accepted 5 December 2008 
the detoxification of xenobiotics. ${ }^{1,2,10,11}$ In diseases of the biliary tree (ie, cholangiopathies, such as primary sclerosing cholangitis (PSC), primary biliary cirrhosis (PBC), liver allograft rejection, and graft-versus-host disease), cholangiocytes are the target cells. ${ }^{1,3}$ Cholangiopathies cause morbidity and mortality and are a major reason for liver transplantation $^{1,3}$ and graft loss. ${ }^{12}$ Cholangiopathies are characterized by patchy rather than diffuse proliferation and loss of differentsized ducts, which suggest that cholangiocytes are heterogeneous and respond differentially to cholestatic diseases and toxin-induced liver injury. ${ }^{1,5,13}$

Recently, the concept of heterogeneity of the rat biliary epithelium has been explored ${ }^{1,5,7,8,10,13-18}$ and classified into three categories: (i) morphological, ${ }^{7,8,14}$ (ii) secretory, ${ }^{7,14,16}$ and (iii) proliferative. ${ }^{5,10,13,15,17-19}$ Morphological heterogeneity-in humans, the biliary ductal system is classified into three different sized segments, which include the extrahepatic bile duct, large bile ducts, and intrahepatic small bile ducts. ${ }^{1,6,9}$ The biliary system extends from the canals of Hering to the large extrahepatic ducts. ${ }^{1,6,9}$ In humans, the intrahepatic biliary epithelium has been divided on the basis of diameter size of the duct: ${ }^{1,6,9}$ small bile ductules $(<15 \mu \mathrm{m})$, interlobular ducts $(15-100 \mu \mathrm{m})$, septal ducts $(100-300 \mu \mathrm{m})$, area ducts $(300-400 \mu \mathrm{m})$, segmental ducts $(400-800 \mu \mathrm{m})$, and hepatic ducts $(>800 \mu \mathrm{m}))^{1,5,6,9}$ Small ductules are lined by $4-5$ cholangiocytes, which are characterized by the presence of a basement membrane and tight junctions between cells and microvilli projecting into the bile duct lumen. ${ }^{5,9,20}$ Small bile ducts join into interlobular ducts ranging from 20 to $100 \mu \mathrm{m}$ in cross-sectional diameter. ${ }^{5,6,9,20}$ In large bile ducts, cholangiocytes are larger and more columnar in shape. ${ }^{6,9,20}$ Similar to humans, a number of in situ (in liver sections) and in vitro (in purified small and large cholangiocytes and isolated small and large intrahepatic bile duct units) studies have shown that the rat intrahepatic biliary epithelium is morphologically heterogeneous. ${ }^{7,8,14}$

\section{Functional heterogeneity}

Following secretion at the bile canaliculus by hepatocytes, ${ }^{21}$ cholangiocytes modify bile as it flows through the biliary tree by a series of hormone-regulated $\mathrm{Ca}^{2+}$ - or cyclic adenosine $3^{\prime}, 5^{\prime}$-monophosphate (cAMP)-dependent reabsorptive and secretory events. ${ }^{4,15,22-30}$ Large, cAMP-responsive rat cholangiocytes express secretin receptors (SRs), cystic fibrosis transmembrane conductance regulator (CFTR), and the chloride bicarbonate anion exchanger $2 \quad\left(\mathrm{Cl}^{-} / \mathrm{HCO}_{3}^{-}\right.$ $\mathrm{AE} 2)^{7,14,16}$ whose activation leads to changes in ductal secretion of water and electrolytes, including $\mathrm{HCO}_{3}^{-}$ions. ${ }^{7,14,16}$ Large cholangiocytes are the only cell types in the liver, which express the SR. ${ }^{7,14,16}$ The pathophysiology of small cholangiocytes is undefined. ${ }^{19}$

\section{Proliferative heterogeneity}

In humans and rodent models, normal cholangiocytes are mitotically dormant. ${ }^{10,31}$ In the human liver, cholangiocyte proliferation is observed in extrahepatic biliary obstruction; during the course of cholestatic liver diseases (eg, PBC, PSC, liver allograft rejection, and graft-versus-host disease) and in response to alcohol, toxins, or drugs. ${ }^{1,3}$ Similar to findings in human cholangiopathies, ${ }^{1,3}$ cholangiocyte proliferation in the rat liver occurs within a limited range of bile duct sizes. ${ }^{1,10,31}$ In rats with extrahepatic cholestasis induced by bile duct ligation (BDL), enhanced cholangiocyte proliferative capacity is restricted to large bile ducts. ${ }^{15,18}$ In this hyperplastic model, cholangiocyte proliferation is closely associated with increased SR gene expression and secretinstimulated cAMP levels, which play a pivotal role in the modulation of cholangiocyte proliferative responses due to cholestasis. ${ }^{4,15,16,26,32,33}$ Despite our knowledge regarding human and rat heterogeneity, information regarding the morphological, proliferative, and functional heterogeneity of mouse intrahepatic biliary epithelium is limited. ${ }^{19}$ With increased availability and usage of transgenic mouse models for studying cholestatic liver disease pathogenesis, we sought to evaluate the morphological, secretory, proliferative, and apoptotic phenotypes of small and large mouse bile ducts in normal and cholestatic models.

\section{MATERIALS AND METHODS Materials}

Reagents were purchased from Sigma Chemical Co. (St Louis, MO, USA) unless otherwise indicated. Porcine secretin was purchased from Peninsula (Belmont, CA, USA). The nuclear dye 4,6-diamidino-2-phenylindole (DAPI) was purchased from Molecular Probes, Inc. (Eugene, OR, USA). The SR (C20) is an affinity-purified goat polyclonal antibody (Santa Cruz Biotechnology Inc., Santa Cruz, CA, USA) raised against a peptide mapping at the $\mathrm{C}$ terminus of SR of human origin and cross-reacts with mouse. ${ }^{19}$ The CFTR monoclonal (IgG1) antibody (M3A7, Thermo Fisher Scientific, Fremont, CA, USA) was raised against the recombinant protein encoding the nucleotide binding fold (NBF2) domain of human CFTR and cross-reacts with mouse. ${ }^{19}$ The anti $\mathrm{Cl}^{-} / \mathrm{HCO}_{3}^{-}$ AE2 (reacting with the chloride bicarbonate anion exchanger $2)^{19}$ is an affinity-purified rabbit anti-rat AE-2 IgG, no. AE21-A, that was purchased from Alpha Diagnostic International (San Antonio, TX, USA). The mouse anti-keratin-19 (KRT-19) antibody (clone RCK105) was purchased from Caltag Laboratories Inc. (Burlingame, CA, USA). The RIA kits for the determination of intracellular cAMP levels were purchased from Perkin Elmer (Shelton, CT, USA).

\section{Animal Model}

Male C57BL/6 mice were purchased from Charles River (Wilmington, MA, USA), maintained in a temperaturecontrolled environment $\left(20-22^{\circ} \mathrm{C}\right)$ with a 12 -h light-dark cycle and fed ad libitum standard chow. Mice had free access to drinking water. Our studies were carried out in: (i) normal mice; and (ii) mice with $\mathrm{BDL}^{34,35}$ for 3 and 7 days. Before each experimental procedure, the animals were anesthetized 
with sodium pentobarbital $(50 \mathrm{mg} / \mathrm{kg}$, i.p.). All animal experiments were performed in accordance with a protocol approved by the Scott and White Institutional Animal Care and Use Committee, and in accordance with the Guide for the Care and Use of Laboratory Animals published by the US National Institutes of Health (NIH Publication nos. 85-23, revised 1996).

\section{In Situ Morphometric Analysis of Intrahepatic Bile Ducts of Normal and BdI Mice}

Morphometric analysis was performed in liver sections from normal and 3-day BDL mice to show that murine bile ducts and cholangiocytes show morphological heterogeneity similar to the rat biliary epithelium. ${ }^{7,8}$ Briefly, two mouse livers from each group were fixed with $2 \%$ paraformaldehyde. The entire livers were dissected into blocks of $2-4 \mu \mathrm{m}^{2}$, processed using standard procedures, embedded in paraffin, sectioned $(5 \mu \mathrm{m})$, and stained for hematoxylin and eosin (H\&E). Morphometrical analysis was performed using a parameter (cutoff level) to recognize and define small ducts as less than $<15 \mu \mathrm{m}$ and having a maximum number of four cholangiocytes lining the bile duct. As the average diameter of a single small cholangiocyte is around $7 \mu \mathrm{m}$, a bile duct lined by four (or less) cholangiocytes should have a diameter $<15 \mu \mathrm{m}$. The usage of the four cholangiocyte per duct parameter reduces the number errors that might be caused by the angle of the section plane. For normal mouse livers, a total of 23 small and 4 large bile ducts were measured using SigmaScan Pro 5.0 (SPSS Inc., Chicago, IL, USA). A total of 250 cholangiocytes were measured (60 from small bile ducts and 113 from large ducts). For BDL mice livers, a total of 41 small, 22 dilated small, and 3 large ducts were measured using SigmaScan Pro 5.0. A total of 466 cholangiocytes were measured (84 from small ducts, 90 from dilated small ducts, 100 from intermediate ducts, 111 from large ducts, and 81 from major ducts).

Purification of Pooled, Small, and Large Cholangiocytes Following standard collagenase perfusion, ${ }^{36}$ a mixed cholangiocyte-enriched suspension was obtained from intact portal tracts of mice as described. ${ }^{36}$ The mixed cholangiocyte-enriched suspension was further separated into two distinct subpopulations of small and large cholangiocytes $(97-100 \% \text { pure by keratin- } 19 \text { immunohistochemistry })^{19,35}$ by counterflow elutriation ( 2500 r.p.m. at the flow rates of 22 and $70 \mathrm{ml} / \mathrm{min}$, respectively) $)^{7,10,16-19}$ using a Beckman J2$21 \mathrm{M}$ centrifuge equipped with a JE-6B rotor (Beckman Instruments Inc., Fullerton, CA, USA). ${ }^{7,10,16-19}$ Following centrifugal elutriation, distinct subpopulations of small and large mouse cholangiocytes were further purified by immunoaffinity separation using a monoclonal antibody, rat IgG2a (provided by Dr R Faris, Providence, RI, USA) against an antigen expressed by cholangiocytes. ${ }^{36}$ The centrifugal elutriation step was excluded for the isolation of pooled mouse cholangiocytes. To assess the degree of contamination by mesenchymal cells, we stained cytospin smears of isolated small, large, and pooled mouse cholangiocytes for vimentin. ${ }^{16}$ Hepatocyte contamination was determined by histochemistry for glucose-6-phosphatase (G-6-P). ${ }^{37}$ Before staining, the immunomagnetic beads used for the purification were detached by enzymatic digestion.

\section{Measurement of Cell Size Distribution in Isolated Pooled, Small, and Large Cholangiocytes from Normal and BDL Mice}

We first determined the cell size distribution in pure pooled cholangiocytes, a fraction that includes small and large cholangiocytes. ${ }^{7,16}$ Pooled mouse cholangiocytes were isolated from normal and 3- and 7-day BDL mice as described above. ${ }^{36}$ Small and large mouse cholangiocytes from normal and 3- and 7-day BDL mice were also evaluated. ${ }^{716}$ Cytospin smears were prepared with approximately 50000 cells per slide. Slides were mounted with $1 \times$ phosphate-buffered saline (PBS). Digital images were obtained by light microscopy with an Olympus BX-40 (Tokyo, Japan) microscope equipped with a camera. The cell diameter of 100-200 cholangiocytes was determined using SigmaScan Pro 5.0. Size calibration was obtained using Polybeads (Dyed Blue $10 \mu \mathrm{m}$, Polyscience Inc., Warrington, PA, USA) as a standard. The diameter of the Polybeads was $9.91 \pm 0.73 \mu \mathrm{m}$.

\section{Effect of BDL on the Proliferation of Small and Large Bile Ducts and Isolated Small and Large Cholangiocytes}

We next performed experiments to evaluate whether (similar to rats $)^{10,15}$ BDL stimulates proliferation of large but not small murine cholangiocytes. Cholangiocyte hyperplasia was measured by determining the number of small $(<15 \mu \mathrm{m})^{14}$ and large $(>15 \mu \mathrm{m})^{14}$ bile ducts in liver sections $(4-5 \mu \mathrm{m}$ thick; three slides evaluated per group of animals) stained with KRT19, ${ }^{35}$ an approach used previously by us. ${ }^{10}$ Sections were evaluated in a coded manner using light microscopy (Nikon, Tokyo, Japan). Over 100 cholangiocytes were counted in three different fields for each group of animals.

The proliferative status of purified small and large cholangiocytes was also determined by cell cycle analysis by fluorescence-activated cell sorting (FACS) ${ }^{38}$ The cells were dissociated in trypsin/EDTA, pelleted by centrifugation, and resuspended at approximately $10^{6}$ cells $/ \mathrm{ml}$ in $1 \times$ PBS containing $0.1 \%$ fetal bovine serum. The cells were fixed in $70 \%$ ice-cold ethanol, followed by incubation in nuclei staining buffer (PI/RNase Staining Buffer, BD Biosciences Pharmingen, San Diego, CA, USA) for $30 \mathrm{~min}$ at $22^{\circ} \mathrm{C}$ according to the manufacturer's recommendations. Cell cycle histograms were generated after analyzing the propidium iodide-stained cells by FACS (FACSCalibur, BD Biosciences, San Jose, CA, USA), in which $10^{4}$ events were recorded for each sample. The samples were analyzed using CellQuest Pro software (BD Biosciences). Cells $\left(1 \times 10^{6}\right)$ were stained with $0.5 \mathrm{ml}$ propidium iodide/RNAse staining buffer $(50 \mu \mathrm{g} / \mathrm{ml}$ propidium iodide, $200 \mu \mathrm{g} / \mathrm{ml}$ DNAse-free RNAse in $1 \times$ PBS containing 
$0.1 \%$ Triton $\mathrm{X}-100$ ) for $30 \mathrm{~min}$ at room temperature and analyzed in the FL3 channel using flow cytometry. The percentage of cells in $G_{0} / G_{1}, S$, and $G_{2} / M$ phases of the cell cycle were determined using software analysis (Modfit LT 3.0, Verify Software House, Topsham, ME, USA). Analysis was performed on singlets, in which cell aggregates were eliminated by gating FL3-Width versus FL3-Area.

\section{Expression of SR, CFTR, $\mathrm{Cl}^{-} / \mathrm{HCO}_{3}^{-} \mathrm{AE2}$, and $\mathrm{KRT} 19$ in Small and Large Bile Ducts in Liver Sections, and Purified Small and Large Cholangiocytes}

We evaluated the expression of SR, CFTR, $\mathrm{Cl}^{-} / \mathrm{HCO}_{3}^{-} \mathrm{AE} 2$, and KRT19 by: (i) immunohistochemistry in paraffin-embedded liver sections $(4-5 \mu \mathrm{m}$ thick; three slides evaluated per group of animals); and (ii) immunofluorescence ${ }^{19}$ in purified small and large cholangiocytes from normal and 3and 7-day BDL mice.

\section{Immunohistochemistry in liver sections}

Liver sections were mounted on glass slides coated with acetone aminopropyltriehoxylan (2\%) solution. After deparaffination, endogenous peroxidase activity was blocked by incubation $(30 \mathrm{~min})$ in methanolic hydrogen peroxide $(2.5 \%)$. Sections were hydrated in graded ethanol and rinsed in $1 \times$ PBS. The endogenous biotin was blocked by the Biotin Blocking System (Dako Cytomation, Glostrup, Denmark). Following washes in $1 \times$ PBS, sections were incubated overnight at $4{ }^{\circ} \mathrm{C}$ with selected primary antibody (1:100 dilution). Samples were rinsed with $1 \times \mathrm{PBS}$, incubated for $10 \mathrm{~min}$ at room temperature with a secondary biotinylated antibody (Dako Cytomation LSAB Plus System-HRP), then with Dako ABC (Dako Cytomation LSAB Plus System-HRP), developed with $3,3^{\prime}$ diaminobenzidine, and counterstained with haematoxylin. For all immunoreactions, negative controls (with preimmune serum substituted for the primary antibody) were included. Blinded observations and light microscopy photographs of liver sections were taken by Leica Microsystems DM 4500 B Light Microscopy (Weltzlar, Germany) with a Jenoptik Prog Res C10 Plus Videocam (Jena, Germany). When $0-5 \%$ of bile ducts were positive for SR, $\mathrm{CFTR}$, or $\mathrm{Cl}^{-} / \mathrm{HCO}_{3}^{-} \mathrm{AE} 2$, we assigned a negative score; a \pm score was assigned when $6-10 \%$ of bile ducts were positive; a + score was assigned when $11-30 \%$ of bile ducts were positive; a ++ score was assigned with $31-60 \%$ of bile ducts positive; and a +++ score was assigned when more than $61 \%$ of bile ducts were positive. Three pathologists in a blinded manner independently performed the evaluations.

Immunofluorescence in small and large mouse cholangiocytes Cytospin smears of purified small and large mouse cholangiocytes were prepared with approximately 50000 cells per slide. The slides were fixed in ice-cold acetone and placed in $1 \times$ PBS and washed for $5 \mathrm{~min}$ at room temperature. Next, the slides were washed three times for $10 \mathrm{~min}$ each at room temperature in PBST $(1 \times$ PBS with $0.2 \%$ Triton X-100) and blocked for $1 \mathrm{~h}$ at room temperature in $4 \%$ bovine serum albumin (BSA) and $1 \times$ PBS. The blocking solution was removed and the coverslips were incubated for $24 \mathrm{~h}$ at $4^{\circ} \mathrm{C}$, with the primary antibodies diluted in 1\% BSA/PBS. Primary antibodies against the following proteins were used: KRT19, SR, CFTR, or $\mathrm{Cl}^{-} / \mathrm{HCO}_{3}^{-} \mathrm{AE} 2$. The next day, slides were washed three times for $10 \mathrm{~min}$ at room temperature in PBST. Next, slides were incubated with Cy3-conjugated anti-rabbit secondary antibody 1:50 (Jackson Immunochemicals, West Grove, PA, USA) in 1\% BSA/PBS at room temperature for $2 \mathrm{~h}$ and washed three times for 10 min each with PBST. Following incubation, slides were washed three times for 10 min each in PBST at room temperature and mounted into microscope slides with Antifade gold containing DAPI as a counterstain (Molecular Probes). Negative controls (with preimmune serum substituted for the primary antibody) were also included. Images were taken by an Olympus IX71 fluorescence microscope with a DP70 digital camera.

\section{Effect of Secretin on Intracellular cAMP Levels and $\mathrm{Cl}^{-}$ Efflux in Freshly Isolated Small and Large Mouse Cholangiocytes}

\section{Intracellular CAMP levels}

We next evaluated the effects of secretin $(100 \mathrm{nM})^{7,16,32,39}$ on intracellular cAMP levels ${ }^{7,16,26,31-33,39}$ and $\mathrm{Cl}^{-}$efflux ${ }^{16,40}$ (two important regulators of secretin-stimulated choleresis) ${ }^{11,16,26,28,30-33,40}$ in small and large cholangiocytes from normal and 7-day BDL mice. Following purification, small and large mouse cholangiocytes were incubated at $37^{\circ} \mathrm{C}$ for $1 \mathrm{~h}$ to regenerate membrane proteins damaged by trypsin digestion during cell isolation. ${ }^{36}$ Subsequently, small and large cholangiocytes $\left(1 \times 10^{5}\right.$ cells $)$ were stimulated at room temperature ${ }^{7,15,16,26,31,32,39}$ with $0.2 \%$ bovine serum albumin (BSA, basal) or secretin $(100 \mathrm{nM})^{7,15,16}$ for 5 min $^{7,15,16,26,31,32,39}$ with $0.2 \%$ BSA. Following stimulation with secretin, 3-isobutylmethylxanthine, a phosphodiesterase inhibitor, ${ }^{41}$ which prevents cAMP degradation, ${ }^{7,15,16}$ was added to small and large cell suspension before ethanol extraction. RIA analysis, ${ }^{7,15,16}$ was performed in accordance with the instructions from the vendor.

\section{$\mathrm{Cl}^{-}$efflux studies}

$\mathrm{Cl}^{-}$efflux was evaluated in freshly isolated small and large cholangiocytes as described. ${ }^{42}$ The fluorescent probe $N$ (ethoxycarbonylmethyl)-6-methoxyquinolinium bromide (MQAE) and 4,4'-diisothiocyanatodihydrostilbene-2,2'-disulfonic acid disodium salt hydrate $\left(\mathrm{H}_{2} \mathrm{DIDS}\right.$, competitive inhibitor of chloride exchange that does not cross the membrane) ${ }^{43}$ were obtained from Invitrogen (Carlsbad, CA, USA). Standard Ringer's solution consisted of: $140 \mathrm{mM} \mathrm{NaCl}$, $5 \mathrm{mM} \mathrm{KCl}, 5 \mathrm{mM}$ (2-hydroxyethyl)- $N$-piperazine $\mathrm{N}$-2 ethanesulfonic acid (HEPES), $1 \mathrm{mM} \mathrm{MgCl}$, and $5 \mathrm{mM}$ glucose, $\mathrm{pH}$ 7.4. In chloride-free Standard Ringer's solution, the chloride salts were exchanged for nitrate salts. $\mathrm{K}^{+}$-rich calibration buffers were made by mixing $150 \mathrm{nM}$ chloride 
solution $(120 \mathrm{mM} \mathrm{KCl}, 1 \mathrm{mM} \mathrm{MgCl}, 27 \mathrm{mM} \mathrm{NaCl}, 5 \mathrm{mM}$ glucose, and $5 \mathrm{mM}$ HEPES) and $150 \mathrm{mM} \mathrm{NO}_{3}^{-}$solutions (chloride exchanged for nitrate) to obtain the desired concentrations of chloride. Briefly, freshly isolated small and large mouse cholangiocytes were loaded with $10 \mathrm{mM}$ MQAE for $1 \mathrm{~h}$, rinsed in Standard Ringer's solution, and allowed to attach to glass coverslips coated with BD Cell-Tak (BD Biosciences, Bedford, MA, USA). Coverslips were placed in a chamber on the stage of an inverted microscope Nikon
Eclipse TE300 (Nikon, Tokyo, Japan). Excitation light was at $355 \mathrm{~nm}$ and emission was measured at $460 \mathrm{~nm}$ using a CCD camera. Centers were bathed in Standard Ringer's solution. Images were captured for $16 \mathrm{~ms}$ every 3-8 s. The basal $\mathrm{Cl}^{-}$ efflux was measured during the exposure of the cells loaded with MQAE to a chloride gradient as described elsewhere. ${ }^{42}$ The fluorescence was expressed as relative change $\left(F_{\text {rel }}\right)$ in fluorescence $(F)$ to the initial fluorescence at the beginning of the experiment $\left(F_{\mathrm{o}}\right)$ according to: $F_{\text {rel }}=F / F_{\mathrm{o}} \times 100(\%)$. The
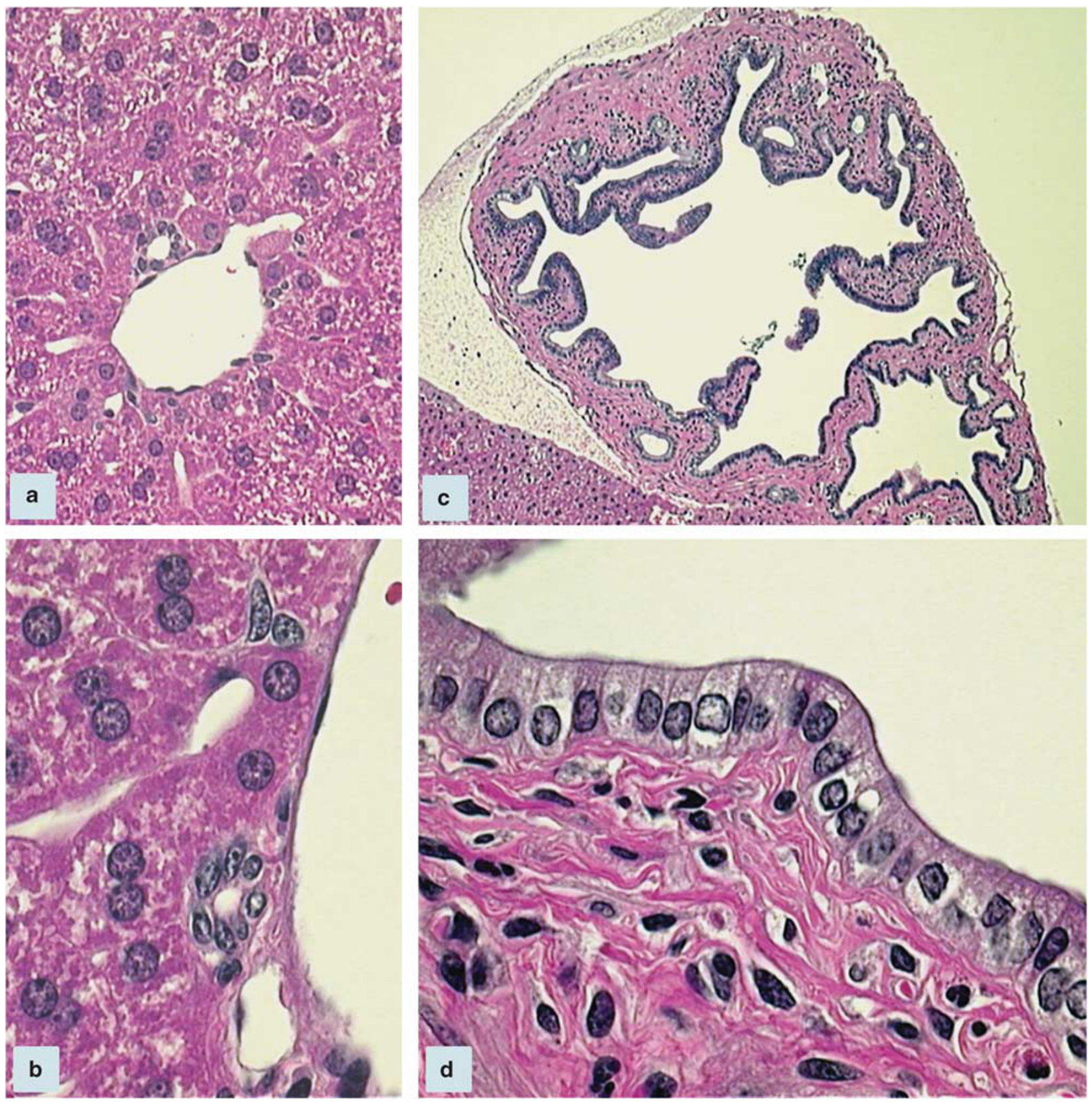

Figure 1 In situ morphometric analysis of liver sections from normal mice. Morphometry of small bile ducts (a) and large bile ducts (c) illustrates the vast differences in bile duct structure and cholangiocyte morphology between small and large bile ducts. Cholangiocytes lining the large ducts (d) appear to be more columnar in morphology compared with small ducts (b). Original magnification: (a) $\times 400,(\mathbf{b}) \times 1000,(\mathbf{c}) \times 100$, and (d) large bile duct $\times 1000$. 
relative chloride efflux rat $\left(J_{\mathrm{Cl}}\right)$ was determined from the first derivative of $F_{\text {rel }}$ with time $\left(\Delta F_{\text {rel }} / \Delta t\right), \% / s$. The efflux through CFTR was determined by subtracting the basal relative efflux $\left(J_{\text {basal }}\right)$ from the cAMP-stimulated relative rate $\left(J_{\text {cAMP }}\right)$, according to: $J_{\text {CFTR }}=J_{\text {cAMP }}-J_{\text {basal. }}$. For each experiment, 4-6 cells were analyzed and the average response was counted as one experimental data point. GraphPad Prism 5.0 software (GraphPad Software, San Diego, CA, USA) was used to determine the value of the $\mathrm{Cl}^{-}$efflux rate.

\section{RESULTS}

In Situ Morphometric Analysis of Intrahepatic Bile Ducts of Normal and BDL Mice

Normal mouse liver sections showed a significant difference in bile duct morphology and size (Figure 1a and c) with cells lining the large ducts appearing to be more columnar com- pared with small ducts (Figure 1b and d). In 3-day BDL mice, the liver sections also showed a significant difference in bile duct morphology and size (not shown) with cells lining the large ducts appearing to be more columnar compared with small ducts, similar to that observed in normal mice liver sections (Figure $1 \mathrm{~b}$ and $\mathrm{d}$ ). In addition, histological examination of liver sections from 3-day BDL mice showed dilatation of small peripheral ducts (Figure 2a and b), and as expected, hepatocyte necrosis and ductal proliferation were also evident (Figure 2c). Small and large bile duct areas of normal and 3day BDL mice were significantly different from each other (Kruskal-Wallis one-way ANOVA on Ranks, $P<0.0001$ ) (Figure 3a). The areas of cholangiocytes lining small and large bile ducts were also found to be significantly different (Kruskal-Wallis one-way ANOVA on Ranks, $P<0.0001$ ) (Figure 3b). The areas (pixel count) of cholangiocytes lining small and large
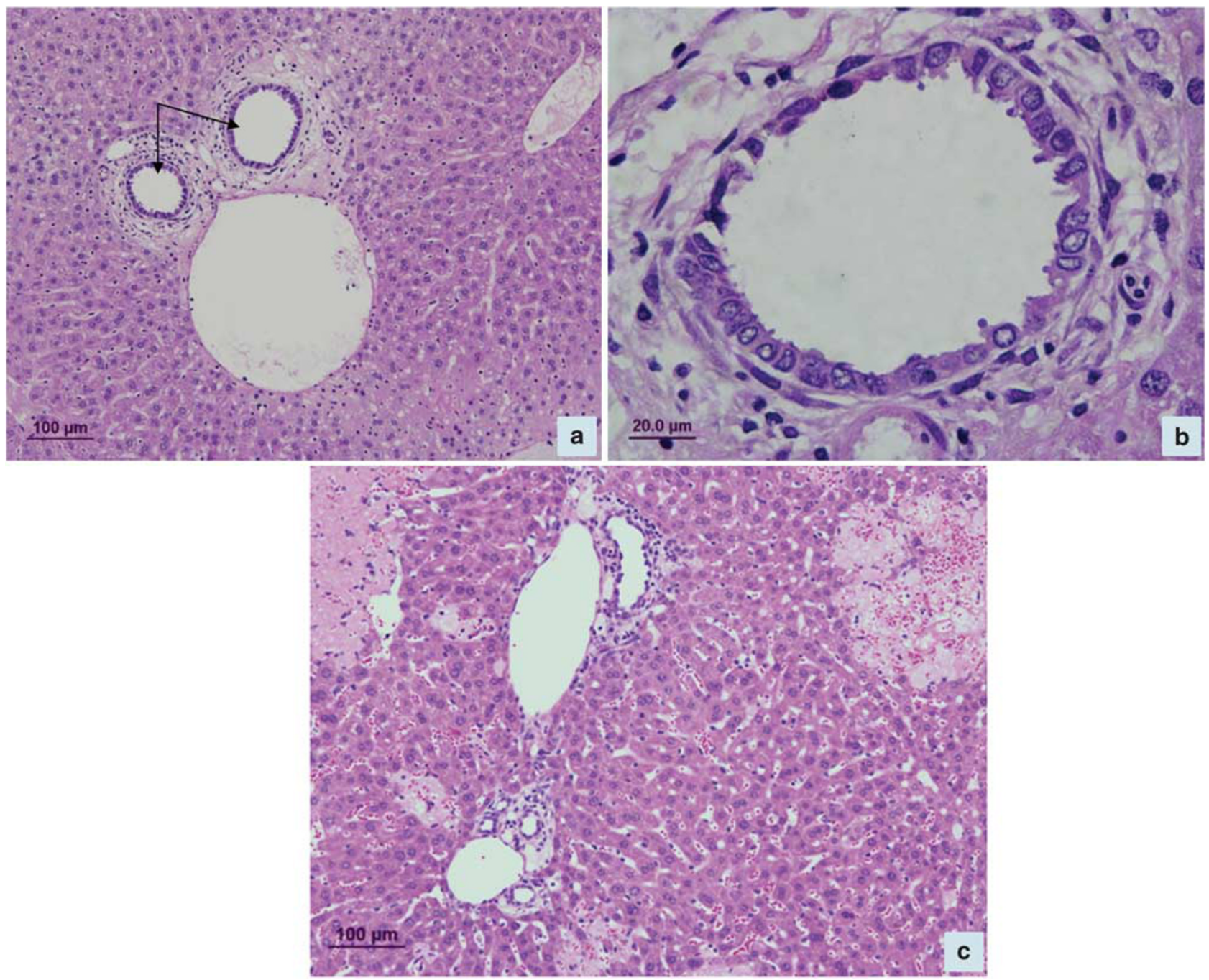

Figure 2 (a) Histological examination of liver sections from 3-day BDL mice stained with H\&E showed dilation of small peripheral ducts indicated by black arrows. (b) Higher magnification view of dilated small peripheral ducts. (c) Hepatocyte necrosis and ductal proliferation were also evident in liver sections from 3-day BDL mice. Size in $\mu \mathrm{m}$ is indicated by black bar. 
bile ducts significantly correlated with bile duct size (Figure $3 \mathrm{~b}$ ), showing that small cholangiocytes line small ducts and larger cholangiocytes line larger ducts.

\section{Cell Size Distribution in Isolated Pooled and Small and Large Cholangiocytes From Normal And BDL Mice}

Cell size distribution was determined in freshly isolated pooled and small and large cholangiocytes from normal and 3- and 7-day BDL mice. The purity of the cells following immunomagnetic isolation was $99-100 \%$ as expected. Vimentin and G-6-P staining for contamination were negative (not shown). Cell size distribution for pooled cholangiocytes is illustrated in Figure 5. A shift in median values of cell size is visible from normal through 7 days of BDL to large cells based upon median cell size (Figure 4). There was a significant difference in the median cell size as determined by ANOVA (Kruskal-Wallis one-way ANOVA, $P<0.0006$ ).
There were no variations in the pooled cell-size distribution of mouse cholangiocytes compared with rat cholangiocytes. ${ }^{7,16}$ Mean cell size $(\mu \mathrm{m})$ for freshly isolated small and large cholangiocytes from normal and 3- and 7-day BDL mice is presented in Table 1 . As expected, there was a significant difference in the mean cell size of small and large cholangiocytes isolated from each treatment groups $(P<0.05$ large $v s$ corresponding small) (Table 1).

\section{BDL Stimulates the Proliferation of Large but not Small Mouse Bile Ducts and Isolated Cholangiocytes}

Small and large bile duct mass expressed as a percentage was evaluated by morphometry of KRT19 stained liver sections. The bile duct mass of large bile ducts was significantly increased in 3- and 7-day BDL mice sections (Figure 5b and c) compared with normal sections (Figure 5a). There were no significant variations in small bile duct mass across the three
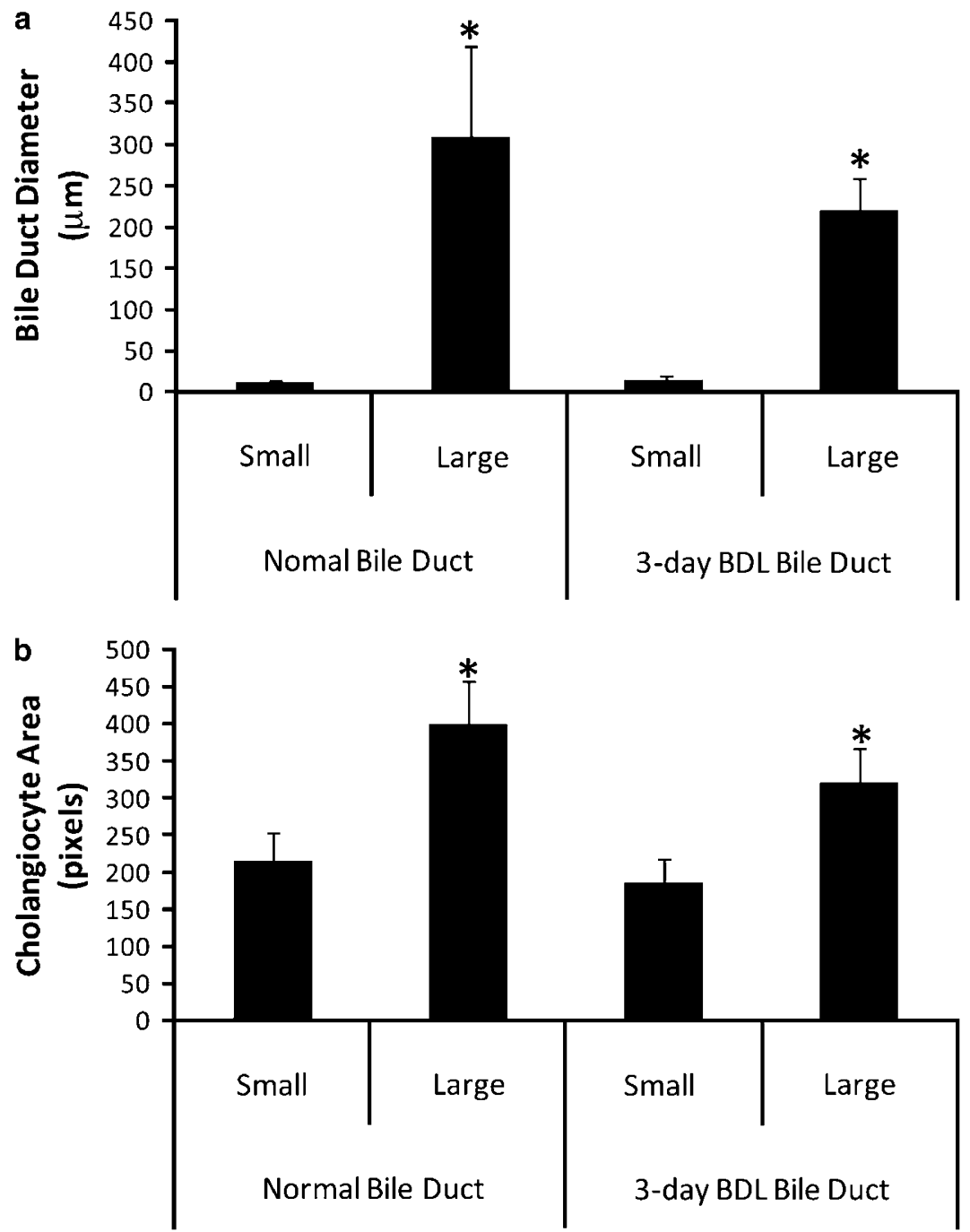

Figure 3 In situ morphometric analysis of liver sections from normal and 3-day BDL mice. (a) Distribution of bile duct sizes ( $\mu \mathrm{m}$ ) classified as small and large bile ducts shows a significant variation in bile duct size. (b) Distribution of cholangiocyte area $\left(\mu \mathrm{m}^{2}\right)$ lining small and large bile ducts indicates a correlation between cholangiocyte size and bile duct diameter (Kruskal-Wallis one-way ANOVA on Ranks, ${ }^{*}<0.0001$ ). BDL $=$ bile duct ligation. 


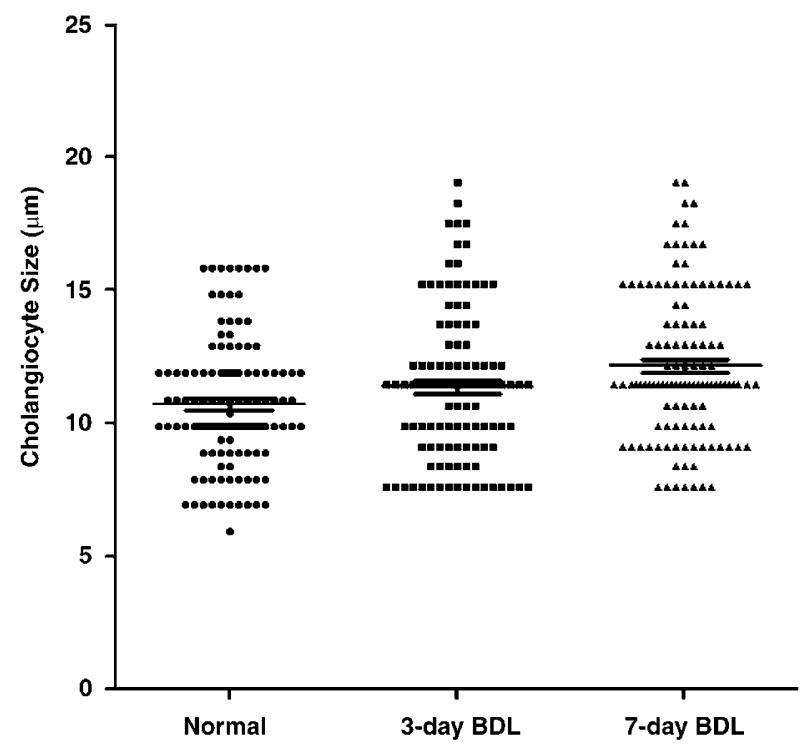

Figure 4 Cell size distribution of freshly isolated pooled cholangiocytes from normal and 3- and 7-day BDL mice. The median size of cholangiocytes is increased in cholangiocytes from 3- and 7-day BDL mice compared with normal cholangiocytes. $\mathrm{BDL}=$ bile duct ligation. treatment groups (Figure 5). Cell cycle distributions of small and large cholangiocytes isolated from normal and 3- and 7day BDL mice were determined using FACS analysis (Table 2). There was a marked increase in the number of large cholangiocytes isolated from 3- and 7-day BDL mice in $\mathrm{G}_{2} / \mathrm{M}$ and $\mathrm{S}$ phase as compared with normal large cholangiocytes (Table 2). There were no significant changes in the cell cycle of small cholangiocytes isolated from the three treatment groups (Table 2).

Table 1 Mean cell sizes of small and large cholangiocytes isolated from normal, BDL 3-, and 7-day BDL mice

\begin{tabular}{lcc}
\hline & Small & Large \\
\hline Normal & $8.84 \pm 0.08$ & $13.24 \pm 0.17^{\&}$ \\
BDL 3-day & $7.98 \pm 0.13$ & $13.04 \pm 0.20^{\&}$ \\
BDL 7-day & $8.02 \pm 0.21$ & $13.72 \pm 0.27^{\&}$
\end{tabular}

$\mathrm{BDL}$, bile duct ligation.

${ }^{\&} P<0.05$ large vs corresponding small cholangiocytes.
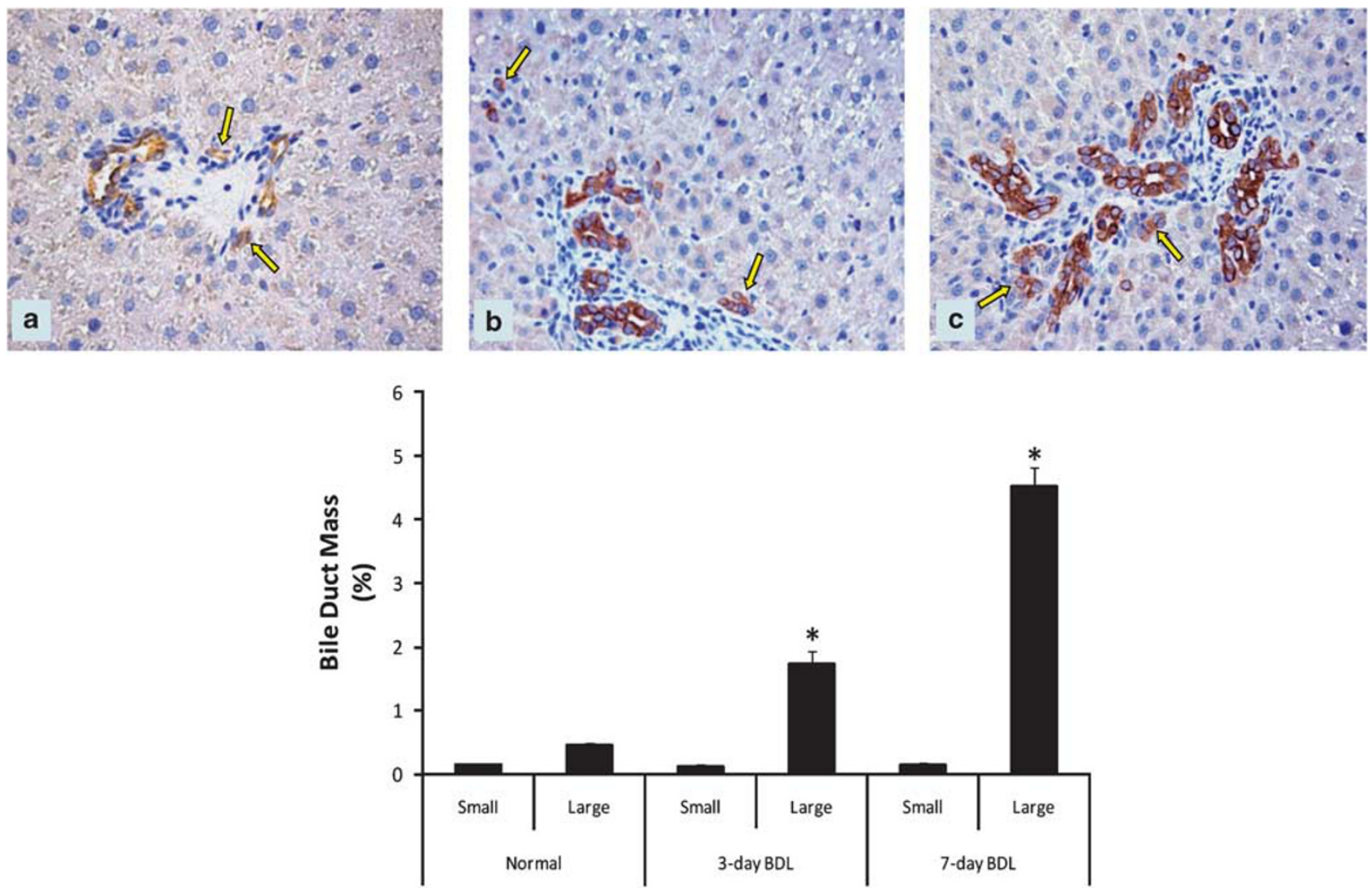

Figure 5 Morphometric evaluation of small and large bile duct mass in liver sections stained with KRT19. There was a significant increase in large (but not small) bile duct mass in (b) 3-day and (c) 7-day BDL mouse liver sections compared with (a) normal liver sections. (Bottom graph) Quantitative data of small and large bile duct mass evaluations. Data are expressed as mean \pm s.e.m. BDL $=$ bile duct ligation. 
Table 2 Cell cycle analysis of small and large cholangiocyte isolated from normal and 3- and 7-day BDL mice

G1 (\%) $\quad$ G2 $(\%) \quad \mathrm{S}(\%)$

$\begin{array}{rlll}\text { Normal } & & & \\ \text { Small } & 99.57 & 0.00 & 0.43 \\ \text { Large } & 96.44 & 0.00 & 3.56\end{array}$

$B D L$ 3-day

Small

99.18

0.12

0.70

Large

86.60

7.29

6.11

BDL 7-day

Small

98.19

0.00

1.81

Large

91.34

3.35

5.31

$\mathrm{BDL}$, bile duct ligation.

The percentage of cells in $G_{0} / G_{1}, S$, and $G_{2} / M$ phases of the cell cycle were determined using software analysis (Modfit LT 3.0). Analysis was performed on singlets, in which cell aggregates were eliminated by gating FL3-Width versus FL3-Area.

\section{Expression of SR, CFTR, $\mathrm{Cl}^{-} / \mathrm{HCO}_{3}^{-} \mathrm{AE2}$, and $\mathrm{KRT} 19$ in Liver Sections and Purified Small and Large Cholangiocytes}

The expression of SR, CFTR, and $\mathrm{Cl}^{-} / \mathrm{HCO}_{3}^{-}$AE2 was measured in liver sections from normal and 3- and 7-day BDL mice by immunohistochemistry (Figure 6 and Table 3). SR, $\mathrm{Cl}^{-} /$ $\mathrm{HCO}_{3}^{-} \mathrm{AE} 2$, and CFTR are expressed by larger bile ducts (Figure 6 and Table 3), whereas small bile ducts are negative (not shown). Following BDL for 3 and 7 days, the expression of $\mathrm{SR}, \mathrm{Cl}^{-} / \mathrm{HCO}_{3}^{-} \mathrm{AE} 2$, and CFTR increased in larger bile ducts compared with large ducts of normal liver sections (Figure 7 and Table 3); in small bile ducts, staining for $\mathrm{SR}, \mathrm{Cl}^{-} / \mathrm{HCO}_{3}^{-}$ $\mathrm{AE} 2$, and CFTR remained negative (not shown). As expected, ${ }^{44}$ CFTR expression is largely apical in nature (Figure 6). When liver sections were incubated with preimmune serum substituted for the primary antibody, the staining was absent (not shown). The semiquantitative expression of $\mathrm{SR}, \mathrm{Cl}^{-} / \mathrm{HCO}_{3}^{-}$ $\mathrm{AE} 2$, and CFTR in small and large ducts in sections from normal and 3- and 7-day BDL mice is shown in Table 3.

The expression of SR, CFTR, and $\mathrm{Cl}^{-} / \mathrm{HCO}_{3}^{-} \mathrm{AE} 2$ was also evaluated by immunofluorescence in freshly isolated small and large cholangiocytes from normal and 3- and 7-day BDL mice (Figure 7). Both small and large cholangiocytes expressed KRT19 (Figure 7). Parallel with the immunohistochemistry (Figure 6), large (but not small) cholangiocytes were positive for SR, CFTR, and $\mathrm{Cl}^{-} / \mathrm{HCO}_{3}^{-}$ AE2 (Figure 7).

Effect of Secretin on Intracellular cAMP Levels and $\mathrm{Cl}^{-}$ Efflux in Small and Large Normal Mouse Cholangiocytes Similar to what was observed in the rat biliary epithelium, ${ }^{7,14,16}$ secretin increased cAMP levels in large (but not small) cholangiocytes isolated from normal and 7-day BDL mice, compared with large cholangiocytes treated with $0.2 \%$ BSA (basal) (Figure 8a). The increase in secretin-stimulated cAMP levels (observed after BDL for 7 days) was higher compared with normal large cholangiocytes (Figure 8a). Similarly, secretin increased $\mathrm{Cl}^{-}$efflux in large cholangiocytes from normal and 7-day BDL mice (Figure 8b). The increase in $\mathrm{Cl}^{-}$efflux observed in large cholangiocytes was higher in 7-day BDL compared with normal large cholangiocytes (Figure 8b).

\section{DISCUSSION}

The morphological and functional heterogeneity of cholangiocytes in rats has been defined during the past years. ${ }^{1,7,10,14-16,18,45}$ Whether a similar morphological, proliferative, and functional profile exists in mice is relatively unknown. ${ }^{19}$ We have developed an SV-40 transformed small and large cholangiocyte cell line from mice, ${ }^{46}$ which have morphological, phenotypic, and functional characteristics similar to that of freshly isolated $\mathrm{rat}^{7,16}$ and mouse ${ }^{19}$ small and large cholangiocytes. However, cholangiocyte heterogeneity has not been explored in situ (in liver sections) and freshly isolated small and large mouse cholangiocytes and liver sections from normal and BDL ( 3 and 7 days postsurgery) mice. We believe that our data on mouse cholangiocyte heterogeneity are critical due to the increased usage of knockout mouse models to study cholestatic liver diseases, such as mdr2 and CGRP knockout mice. ${ }^{35,47}$

The morphological and functional diversity of epithelial cells in other organs including kidney, ${ }^{48,49}$ the small intestine, ${ }^{50,51}$ and parenchyma liver, ${ }^{52,53}$ and the rat biliary epithelium $^{1,5,7,10,13-18}$ is well defined. Indeed, only the epithelial cells of the proximal tubule and descending limb of Henle's loop have transepithelial water secretory activity modulated by aquaporin channels (CHIP28). ${ }^{54}$ The epithelial cells of the small and large intestine are heterogeneous regarding the distribution of the membrane transporters regulating the absorptive and secretory functions. ${ }^{50}$ In the liver, periportal and perivenous parenchymal cells are heterogeneous regarding the metabolism of oxidative energy, carbohydrate, and amino acids. ${ }^{52}$ Furthermore, the expression of transporters regulating bile secretion is heterogeneous among hepatocytes of different lobular zones. ${ }^{53}$ Although the heterogeneity of the rat biliary epithelium is well established, limited information exists ${ }^{19}$ regarding the possible functional diversity of different-sized mouse cholangiocytes.

We first showed that the biliary epithelium of normal mice is morphologically heterogeneous with smaller cholangiocytes lining small bile ducts and larger cholangiocytes lining larger ducts. The latter data are important, as it allows the direct correlation of studies on purified subpopulations of small and large cholangiocytes to specific bile duct segments in the intrahepatic mouse biliary tree. Our present findings parallel closely what has been shown in the rat ductal biliary system. Indeed, we have shown that the rat biliary tree is 

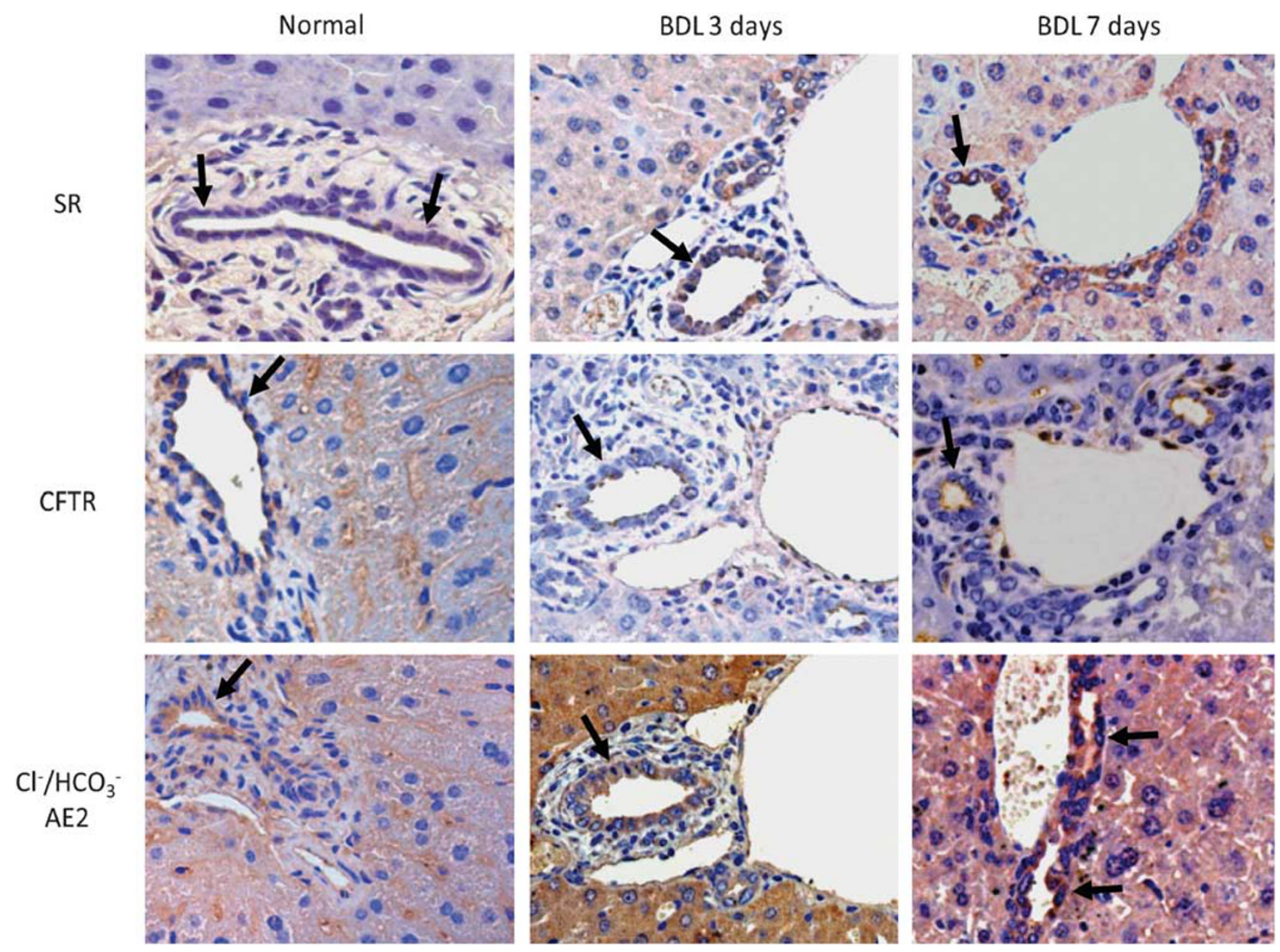

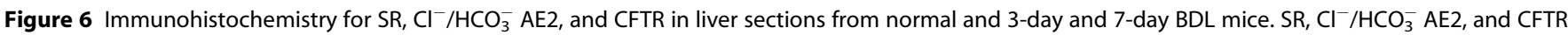
are expressed by larger bile ducts, whereas small bile ducts are negative (not shown). Following $\mathrm{BDL}$ for 3 and 7 days, the expression of SR, $\mathrm{Cl}^{-} / \mathrm{HCO}_{3}^{-} \mathrm{AE}^{-}$, and CFTR increases in larger bile ducts compared with large dusts of normal liver sections; in small bile ducts, staining for SR, $\mathrm{Cl}^{-} / \mathrm{HCO}_{3}^{-} \mathrm{AE2}$, and $\mathrm{CFTR}^{-}$ remained negative (not shown). Arrows indicate large bile ducts. $\mathrm{BDL}=$ bile duct ligation; $\mathrm{Cl}^{-} / \mathrm{HCO}_{3}^{-} \mathrm{AE2}=$ chloride bicarbonate anion exchanger 2 ; $\mathrm{CFTR}=$ cystic fibrosis transmembrane conductance regulator; $\mathrm{SR}=$ secretin receptor.

Table 3 Semiquantitative expression of $\mathrm{SR}, \mathrm{Cl}^{-} / \mathrm{HCO}_{3}^{-}$AE2, and CFTR in liver sections from normal, 3-day BDL and 7-day BDL mice

\begin{tabular}{|c|c|c|c|c|c|c|}
\hline & \multicolumn{2}{|c|}{ Normal } & \multicolumn{2}{|c|}{3 days $\mathrm{BDL}$} & \multicolumn{2}{|c|}{7 days $\mathrm{BDL}$} \\
\hline & Small & Large & Small & Large & Small & Large \\
\hline SR & - & + & $+/-$ & +++ & $+/-$ & +++ \\
\hline $\mathrm{Cl}^{-} / \mathrm{HCO}_{3}^{-} \mathrm{AE} 2$ & - & ++ & $+/-$ & +++ & $+/-$ & +++ \\
\hline CFTR & - & + & $+/-$ & ++ & $+/-$ & ++ \\
\hline
\end{tabular}

$\mathrm{BDL}$, bile duct ligation; $\mathrm{Cl}^{-} / \mathrm{HCO}_{3}^{-} \mathrm{AE2}$, chloride bicarbonate anion exchanger 2; SR, secretin receptor.

Parameters for the semiquantitative evaluation of $\mathrm{SR}, \mathrm{Cl}^{-} / \mathrm{HCO}_{3}^{-} \mathrm{AE} 2$, and $\mathrm{CFTR}$ in liver sections $(5 \mu \mathrm{m}$ thick; three slides evaluated per group of animals). $\mathrm{CFTR}=$ cystic fibrosis transmembrane conductance regulator.

Grading: $0-5 \%=-; 6-10 \%=+/-; 11-30 \%=+; 31-60 \%=++;>61 \%=+++$. composed of bile ducts of different sizes (small ducts lined by small cells and larger ducts lined by larger cholangiocytes), which range in size from 5 to $200 \mu \mathrm{m}$ in external diameter. ${ }^{7}$ On the basis of morphological, phenotypic, and functional differences among ducts of different diameter in a rat model, we have recently classified the intrahepatic bile duct system into small $(<15 \mu \mathrm{m})$ and large $(>15 \mu \mathrm{m})$ ducts. ${ }^{14}$ Similar results were obtained in normal rats by Benedetti $e t a l^{8}$, who demonstrated that: (i) the diameter of intrahepatic bile ducts ranges from 5 to $100 \mu \mathrm{m}$, and the area of lining cholangiocytes ranges from 8 to $100 \mu \mathrm{m}$; and (ii) a highly significant linear relationship existed between duct diameter and cholangiocyte diameter. During the model of cholestasis induced by BDL, there were similar differences in bile duct morphology, which was consistent with what was observed in normal mice. As expected, histological examination of BDL mice liver sections also showed hepatocyte necrosis and the 
a

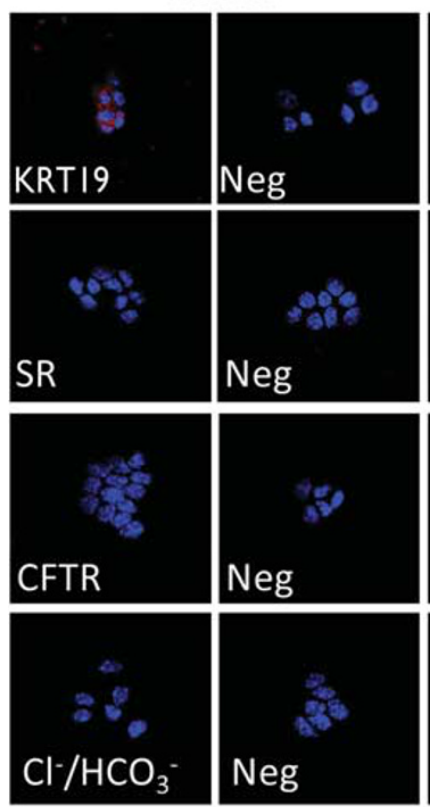

Small
Normal
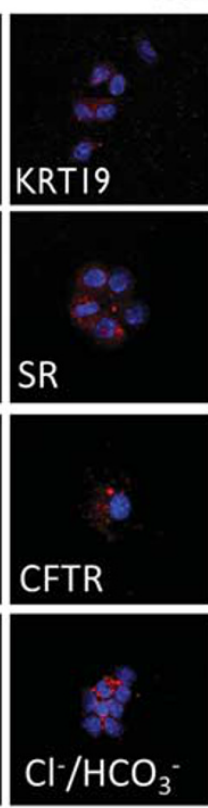

Large
BDL 3 days
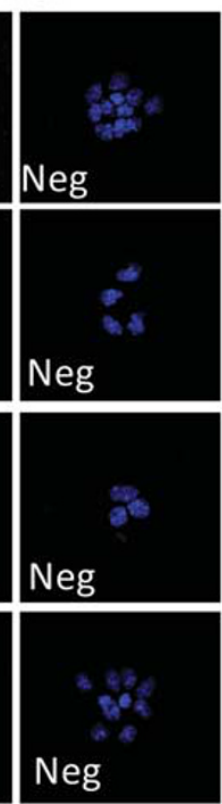

BDL 7 days
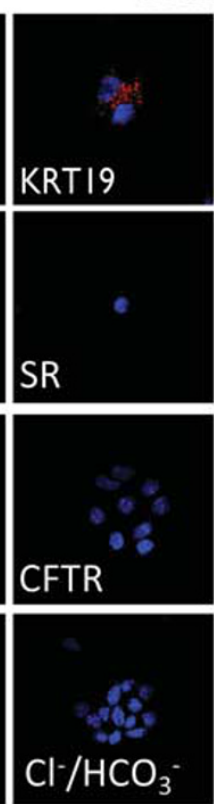

Small

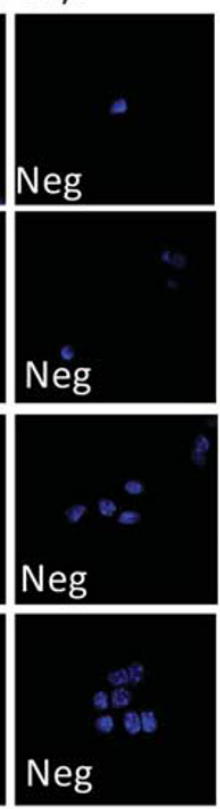

BDL 7 days
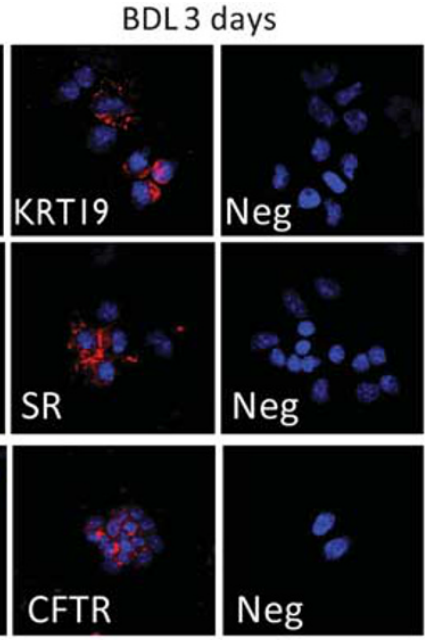

b
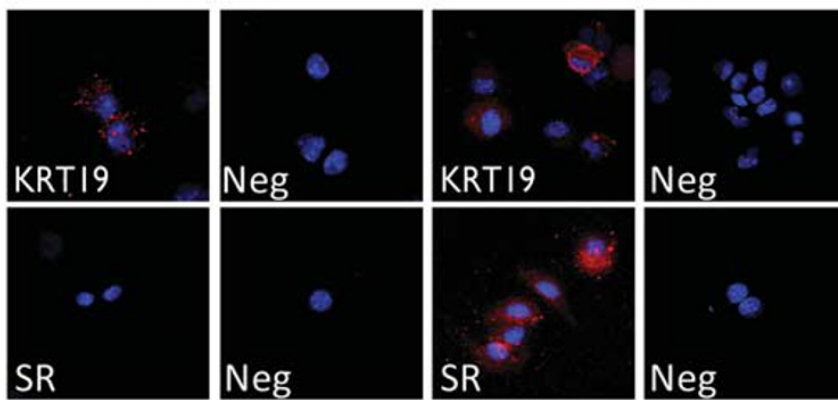

\section{Neg}

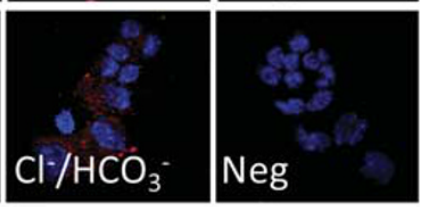

Large

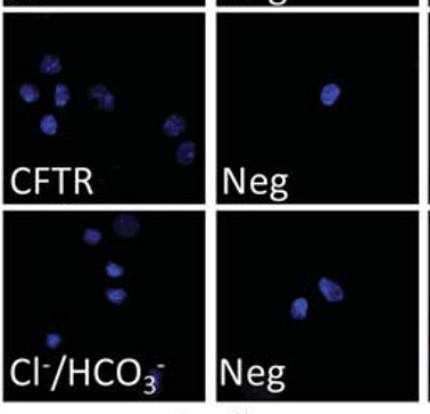

Small

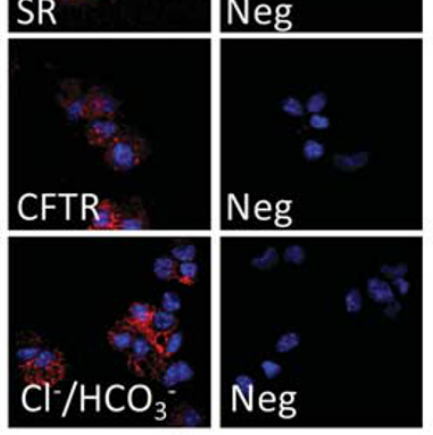

Large

Figure 7 Immunofluorescence for $\mathrm{KRT} 19, \mathrm{SR}, \mathrm{Cl}^{-} / \mathrm{HCO}_{3}^{-} \mathrm{AE2}$, and CFTR expression in freshly isolated small and large cholangiocytes from (a) normal, 3- and (b) 7-day BDL mice. Both small and large cholangiocytes from normal and 3- and 7-day BDL mice express KRT19. Large (but not small) cholangiocytes from normal and 3- and 7-day BDL mice were positive for SR, CFTR, and $\mathrm{Cl}^{-} / \mathrm{HCO}_{3}^{-} \mathrm{AE2}$. Scale bar $=50 \mu \mathrm{m}$. BDL $=$ bile duct ligation; $\mathrm{KRT} 19=\mathrm{keratin}-19$; $\mathrm{Cl}^{-} / \mathrm{HCO}_{3}^{-}=$chloride bicarbonate anion exchanger 2; CFTR = cystic fibrosis transmembrane conductance regulator; $\mathrm{SR}=$ secretin receptor; Neg $=$ negative.

dilation of small peripheral bile ducts. ${ }^{15,16}$ In 3-day BDL mice, the size of the cholangiocytes correlated with bile ducts diameter in situ, with small cholangiocytes lining small bile ducts and larger cholangiocytes lining larger bile ducts.

We have demonstrated previously that BDL induces the proliferation of large but not small rat cholangiocytes. ${ }^{16,18}$
Consistent with those findings, ${ }^{16,18}$ we found, by KRT19 morphometry for small and large ducts in liver sections and by FACS analysis of the cell cycle of small and large cholangiocytes isolated from normal and 3- and 7-day mice, that there was selective proliferation of large but not small mouse cholangiocytes. These findings clearly show that 

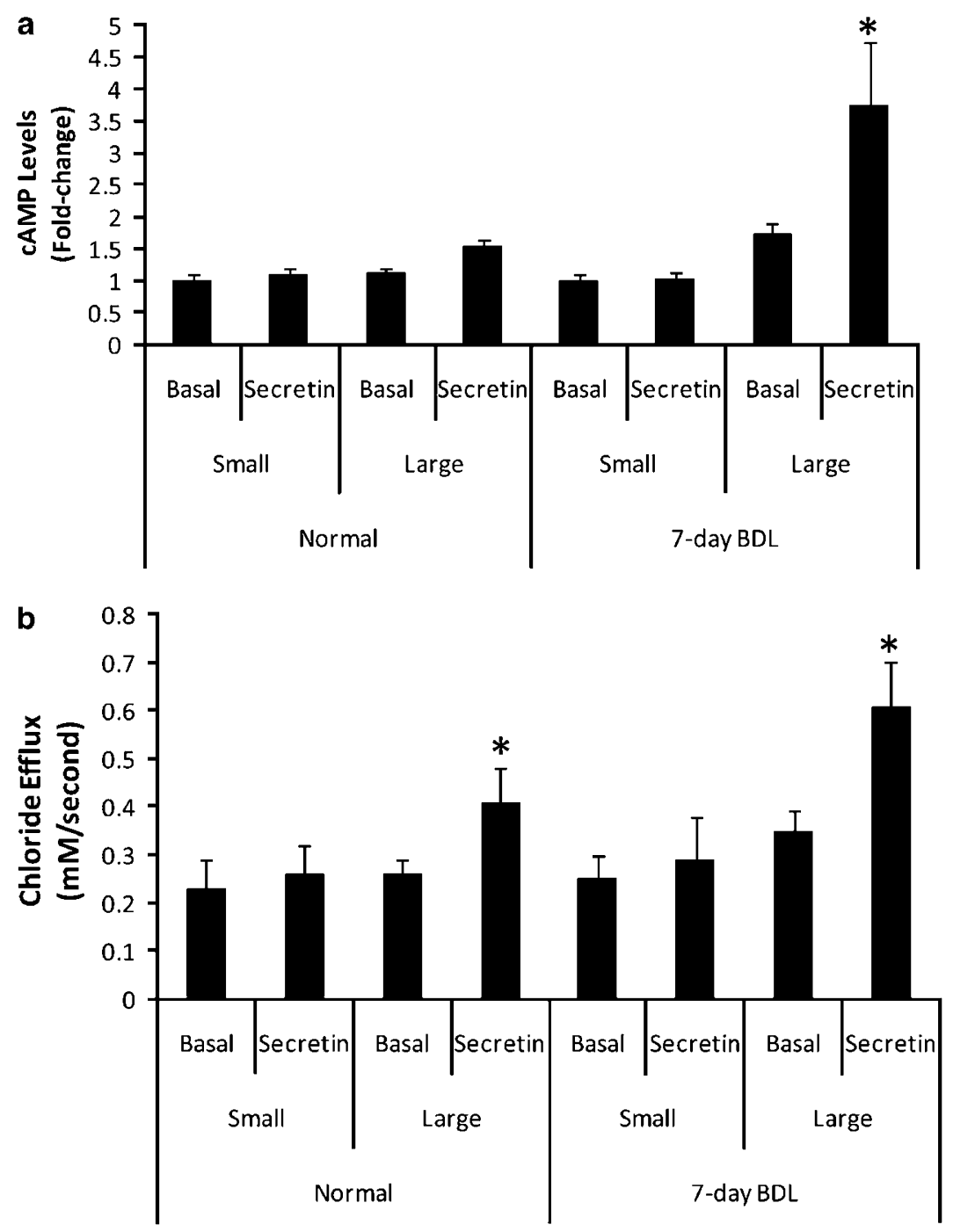

Figure 8 Effects of secretin on (a) intracellular cAMP levels and (b) $\mathrm{Cl}^{-}$efflux of small and large cholangiocytes. (a) Secretin (100 nM) increased cAMP levels in large (but not small) cholangiocytes isolated from normal and 7-day BDL mice compared with large cholangiocytes treated with $0.2 \%$ BSA (basal). Data are mean \pm s.e.m. of eight experiments. ${ }^{*} P<0.05$ vs corresponding basal value. The increase in secretin-stimulated cAMP levels (observed after BDL for 7 days) was higher compared with normal large cholangiocytes. (b) Secretin (100 nM) increased $\mathrm{Cl}^{-}$efflux of large (but not small) cholangiocytes isolated from normal and 7-day BDL mice. Values are the mean \pm s.e.m.; $n=4$ experiments for small cholangiocytes, and $n=6$ experiments for large cholangiocytes for both normal and 7-day BDL. ${ }^{\star} P<0.05$ vs corresponding basal value.

cholangiocytes from mice have the same proliferative heterogeneity profile as rats supporting the use of the mouse model of BDL for studies elucidating the proliferative responses of small and large cholangiocytes to extrahepatic cholestasis.

Next, we evaluated the heterogeneous expression of functional markers of cholangiocytes, such as SR, CTFR, and $\mathrm{Cl}^{-}$/ $\mathrm{HCO}_{3}^{-}$, which are involved in the regulation of cholangiocyte secretory and proliferative activities. ${ }^{1,5,7,10,13-18}$ Previous work has shown that large cholangiocytes from rats are functionally active (ie, respond to secretin) and express SR, CFTR, and the $\mathrm{Cl}^{-} / \mathrm{HCO}_{3}^{-}$exchanger., ${ }^{5,7,13,14,16}$ Similar to rats, ${ }^{5,7,13,14,16}$ we found that large but not small cholangiocytes and bile ducts express SR, CFTR, and $\mathrm{Cl}^{-} / \mathrm{HCO}_{3}^{-}$exchanger, indicating that large cholangiocyte from mice are functionally active, cAMP-responsive, and heterogeneous in response to cholestasis induced by $\mathrm{BDL}$. The heterogeneous secretory and proliferative activities of the mouse biliary epithelium were further supported by the enhanced cAMP levels and $\mathrm{Cl}^{-}$efflux (in response to secretin) in large but not small cholangiocytes from normal and BDL mice. The pathophysiology of small cholangiocytes is largely unknown. To compensate for the loss of large, cAMP-dependent cholangiocyte function, small rat cholangiocytes have been shown to proliferate and develop de novo SR gene expression and secretin-stimulated secretory activity. ${ }^{10,18}$ Our recent studies ${ }^{19}$ showed that small murine cholangiocytes proliferate by activation (in response to $\mathrm{H} 1$ histamine receptor agonists) of the $\mathrm{IP}_{3}$-CaMK I-CREB pathway, ${ }^{19}$ which is independent from the cAMP-dependent pathway shown in large cholangiocytes. ${ }^{5,7,13-16}$ 
In conclusion, we have demonstrated that small and large bile ducts and small and large cholangiocytes from normal and BDL mice show morphological, proliferative, and functional heterogeneity. Our present findings show that the biliary system in mice has morphological, proliferative, and secretory heterogeneity similar to the normal and BDL rat models, ${ }^{5,7,8,13-16}$ thereby supporting the usage of genetically modified mouse models in the study of biliary heterogeneity and cholestatic liver diseases. This information on the heterogeneity of biliary epithelium in the mouse will be valuable for future studies examining cholestatic liver disease pathogenesis. In particular, factors and signaling mechanisms controlling the heterogeneous responses of small and large cholangiocytes during cholestatic liver diseases and exposure to liver toxins can be addressed in specific transgenic mouse models for key proteins thought to play a role in biliary proliferation.

\section{ACKNOWLEDGEMENTS}

We thank Dr Andreea Trache and Anna Webb of the Texas A\&M University Health Science Center Microscopy Imaging Center for assistance with confocal microscopy. This work was supported by the Dr Nicholas C Hightower Centennial Chair of Gastroenterology to Dr Alpini from Scott and White Hospital, a VA Research Scholar Award, a VA Merit Award, and the NIH grants DK054811 and DK062975 to Dr Alpini, by a grant from MIUR (PRIN) 2007 no. 2007HPT7BA_001), University and Faculty funds (Professor Eugenio Gaudio), by MIUR (PRIN) grants no. 2007, prot. HPT7BA_003 to Professor Alvaro, and an NIH K01 grant award (DK078532) to Dr DeMorrow.

1. Alpini G, Prall RT, LaRusso NF. The pathobiology of biliary epithelia. In: I M Arias, J L Boyer, F V Chisari, N Fausto, W Jakoby, D Schachter, and D A Shafritz D (eds). The Liver; Biology \& Pathobiology, 4th edn. Lippincott Williams \& Wilkins: Philadelphia, PA, 2001, pp 421-435.

2. Alvaro $D$, Mancino MG, Glaser $S$, et al. Proliferating cholangiocytes: a neuroendocrine compartment in the diseased liver. Gastroenterology 2007;132:415-431.

3. Lazaridis KN, Strazzabosco M, LaRusso NF. The cholangiopathies: disorders of biliary epithelia. Gastroenterology 2004;127:1565-1577.

4. Alpini $G$, Lenzi $R$, Sarkozi $L$, et al. Biliary physiology in rats with bile ductular cell hyperplasia. Evidence for a secretory function of proliferated bile ductules. J Clin Invest 1988;81:569-578.

5. Kanno N, LeSage G, Glaser S, et al. Functional heterogeneity of the intrahepatic biliary epithelium. Hepatology 2000;31:555-561.

6. Ludwig J. New concepts in biliary cirrhosis. Sem Liver Dis 1987;7: 293-301.

7. Alpini G, Roberts S, Kuntz SM, et al. Morphological, molecular, and functional heterogeneity of cholangiocytes from normal rat liver. Gastroenterology 1996;110:1636-1643.

8. Benedetti A, Bassotti C, Rapino $K$, et al. A morphometric study of the epithelium lining the rat intrahepatic biliary tree. J Hepatol 1996;24:335-342.

9. Schaffner $\mathrm{F}$, Popper $\mathrm{H}$. Electron microscopic studies of normal and proliferated bile ductules. Am J Pathol 1961;38:393-410.

10. LeSage $G$, Benedetti $A$, Glaser $S$, et al. Acute carbon tetrachloride feeding selectively damages large, but not small, cholangiocytes from normal rat liver. Hepatology 1999;29:307-319.

11. Kanno N, LeSage G, Glaser S, et al. Regulation of cholangiocyte bicarbonate secretion. Am J Physiol Gastrointest Liver Physiol 2001;281:G612-G625.

12. Neil DA, Hubscher SG. Histologic and biochemical changes during the evolution of chronic rejection of liver allografts. Hepatology 2002;35:639-651.

13. Marzioni M, Glaser SS, Francis $H$, et al. Functional heterogeneity of cholangiocytes. Semin Liver Dis 2002;22:227-240.
14. Alpini G, Glaser S, Robertson W, et al. Large but not small intrahepatic bile ducts are involved in secretin-regulated ductal bile secretion. Am J Physiol Gastroint Liver Physiol 1997;272:G1064-G1074.

15. Alpini G, Glaser S, Ueno Y, et al. Heterogeneity of the proliferative capacity of rat cholangiocytes after bile duct ligation. Am J Physiol Gastrointest Liver Physiol 1998;274:G767-G775.

16. Alpini $G$, Ulrich $C$, Roberts $S$, et al. Molecular and functional heterogeneity of cholangiocytes from rat liver after bile duct ligation. Am J Physiol Gastrointest Liver Physiol 1997;272: G289-G297.

17. LeSage $G$, Glaser $S$, Ueno $Y$, et al. Regression of cholangiocyte proliferation after cessation of ANIT feeding is coupled with increased apoptosis. Am J Physiol Gastrointest Liver Physiol 2001;281: G182-G190.

18. LeSage G, Glaser SS, Marucci L, et al. Acute carbon tetrachloride feeding induces damage of large but not small cholangiocytes from BDL rat liver. Am J Physiol Gastrointest Liver Physiol 1999;276:G1289G1301.

19. Francis $\mathrm{H}$, Glaser $\mathrm{S}$, DeMorrow $\mathrm{S}$, et al. Small mouse cholangiocytes proliferate in response to $\mathrm{H} 1$ histamine receptor stimulation by activation of the $\mathrm{IP}_{3} / \mathrm{CaMK} \mathrm{I} / \mathrm{CREB}$ pathway. Am J Physiol Cell Physiol 2008:295:C499-C513.

20. Steiner JW, Carruthers JS. Studies on the fine structure of the terminal branches of the biliary tree. I. The morphology of normal bile canaliculi, bile preductules (ducts of Hering) and bile ductules. Am J Pathol 1961;38:639-661.

21. Nathanson $\mathrm{MH}$, Boyer JL. Mechanisms and regulation of bile secretion. Hepatology 1991;14:551-566.

22. Alpini G, Glaser S, Robertson W, et al. Bile acids stimulate proliferative and secretory events in large but not small cholangiocytes. Am J Physiol Gastroint Liver Physiol 1997;273:G518-G529.

23. Alpini $G$, Lenzi $R$, Zhai $W$-R, et al. Bile secretory function of intrahepatic biliary epithelium in the rat. Am J Physiol Gastroint Liver Physiol 1989;257:G124-G133.

24. Alvaro D, Cho WKC, Mennone A, et al. Effect of secretin on intracellular $\mathrm{pH}$ regulation in isolated rat bile duct epithelial cells. J Clin Invest 1993;92:1314-1325.

25. Alvaro D, Alpini G, Jezequel AM, et al. Role and mechanisms of action of acetylcholine in the regulation of rat cholangiocyte secretory functions. J Clin Invest 1997;100:1349-1362.

26. Glaser S, Rodgers RE, Phinizy JL, et al. Gastrin inhibits secretin-induced ductal secretion by interaction with specific receptors on rat cholangiocytes. Am J Physiol Gastrointest Liver Physiol 1997:273:G1061-G1070.

27. Glaser S, Alvaro D, Roskams T, et al. Dopaminergic inhibition of secretin-stimulated choleresis by increased PKC- $\gamma$ expression and decrease of PKA activity. Am J Physiol Gastrointest Liver Physiol 2003:284:G683-G694.

28. LeSage $G$, Alvaro D, Benedetti $A$, et al. Cholinergic system modulates growth, apoptosis, and secretion of cholangiocytes from bile ductligated rats. Gastroenterology 1999;117:191-199.

29. LeSage G, Alvaro D, Glaser S, et al. Alpha-1 adrenergic receptor agonists potentiate secretin-stimulated choleresis of bile duct ligated rats by $\mathrm{Ca}^{2+}$ - and PKC-dependent stimulation of CAMP synthesis. Hepatology 2004;40:1116-1127.

30. LeSage G, Marucci L, Alvaro $D$, et al. Insulin inhibits secretin-induced ductal secretion by activation of PKC alpha and inhibition of PKA activity. Hepatology 2002;36:641-651.

31. LeSage G, Glaser S, Gubba S, et al. Regrowth of the rat biliary tree after $70 \%$ partial hepatectomy is coupled to increased secretin-induced ductal bile secretion. Gastroenterology 1996;111: 1633-1644.

32. Glaser $S$, Benedetti $A$, Marucci $L$, et al. Gastrin inhibits cholangiocyte growth in bile duct-ligated rats by interaction with cholecystokinin-B/ gastrin receptors via D-myo-inositol 1,4,5-triphosphate-, $\mathrm{Ca}\left({ }^{2+}\right)$-, and protein kinase $\mathrm{C}$ alpha-dependent mechanisms. Hepatology 2000:32:17-25

33. Tietz PS, Alpini G, Pham LD, et al. Somatostatin inhibits secretininduced ductal hypercholeresis and exocytosis by cholangiocytes. Am J Physiol Gastrointest Liver Physiol 1995;269:G110-G118.

34. Miyoshi H, Rust C, Guicciardi ME, et al. NF-kappaB is activated in cholestasis and functions to reduce liver injury. Am J Pathol 2001;158:967-975. 
35. Glaser S, Ueno Y, DeMorrow S, et al. Knockout of alpha-calcitonin gene-related peptide reduces cholangiocyte proliferation in bile duct ligated mice. Lab Invest 2007;87:914-926.

36. Ishii M, Vroman B, LaRusso NF. Isolation and morphological characterization of bile duct epithelial cells from normal rat liver. Gastroenterology 1989;97:1236-1247.

37. Teutsch HF. Improved method for the histochemical demonstration of glucose-6-phosphatase activity. Histochemistry 1978;57:107-117.

38. Kalejta RF, Shenk T, Beavis AJ. Use of a membrane-localized green fluorescent protein allows simultaneous identification of transfected cells and cell cycle analysis by flow cytometry. Cytometry 1997;29: 286-291.

39. Kato A, Gores GJ, LaRusso NF. Secretin stimulates exocytosis in isolated bile duct epithelial cells by a cyclic AMP-mediated mechanism. J Biol Chem 1992;267:15523-15529.

40. McGill JM, Basavappa S, Gettys TW, et al. Secretin activates Cl channels in bile duct epithelial cells through a cAMP-dependent mechanism. Am J Physiol Gastroint Liver Physiol 1994;266:G731-G736.

41. Rapundalo ST, Solaro RJ, Kranias EG. Inotropic responses to isoproterenol and phosphodiesterase inhibitors in intact guinea pig hearts: comparison of cyclic AMP levels and phosphorylation of sarcoplasmic reticulum and myofibrillar proteins. Circ Res 1989;64: 104-111.

42. Servetnyk Z, Krjukova J, Gaston B, et al. Activation of chloride transport in CF airway epithelial cell lines and primary CF nasal epithelial cells by S-nitrosoglutathione. Respir Res 2006;7:124.

43. Furuya W, Tarshis T, Law FY, et al. Transmembrane effects of intracellular chloride on the inhibitory potency of extracellular H2DIDS Evidence for two conformations of the transport site of the human erythrocyte anion exchange protein. J Gen Physiol 1984;83:657-681.

44. Fiorotto R, Spirli C, Fabris L, et al. Ursodeoxycholic acid stimulates cholangiocyte fluid secretion in mice via CFTR-dependent ATP secretion. Gastroenterology 2007;133:1603-1613.
45. Alpini G, Glaser S, Ueno $Y$, et al. Bile acid feeding induces cholangiocyte proliferation and secretion: evidence for bile acidregulated ductal secretion. Gastroenterology 1999;116:179-186.

46. Ueno Y, Alpini G, Yahagi K, et al. Evaluation of differential gene expression by microarray analysis in small and large cholangiocytes isolated from normal mice. Liver Int 2003;23:449-459.

47. Trauner M, Fickert $P$, Wagner M. MDR3 (ABCB4) defects: a paradigm for the genetics of adult cholestatic syndromes. Semin Liver Dis 2007;27:77-98.

48. Tsuruoka S, Takeda M, Yoshitomi K, et al. Cellular heterogeneity of ammonium ion transport across the basolateral membrane of the hamster medullary thick ascending limb of Henle's loop. J Clin Invest 1993;92:1881-1888.

49. Guggino WB. Functional heterogeneity in the early distal tubule of the Amphiuma kidney: evidence for two modes of $\mathrm{Cl}^{-}$and $\mathrm{K}^{+}$transport across the basolateral cell membrane. Am J Physiol Renal Physiol 1986;250:F430-F440

50. Knickelbein RG, Aronson PS, Dobbins JW. Membrane distribution of sodium-hydrogen and chloride-bicarbonate exchangers in crypt and villus cell membranes from rabbit ileum. J Clin Invest 1988;82: 2158-2163.

51. Fromm M, Hegel U. Segmental heterogeneity of epithelial transport in rat large intestine. Pflugers Arch 1978;378:71-83.

52. Katz N, Jungermann K. Metabolic heterogeneity of the liver. In: Tavoloni N, Berk PD (eds). Hepatic Transport and Bile Secretion: Physiology and Pathophysiology. Raven Press: New York, 1993, pp 55-70.

53. Groothuis GM, Meijer DK. Hepatocyte heterogeneity in bile formation and hepatobiliary transport of drugs. Enzyme 1992;46: 94-138.

54. Nielsen S, Smith BL, Christensen El, et al. CHIP28 water channels are localized in constitutively water-permeable segments of the nephron. J Cell Biol 1993;120:371-383. 